\title{
Desenvolvimento e caracterização de hambúrguer vegano de grão de bico (Cicer arietinum L.) com adição de ora-pro-nóbis (Pereskia aculeata Mill.)
}

\author{
Development and characterization of chickpeas (Cicer arietinum L.) vegan hamburguer with ora- \\ pro-nóbis (Pereskia Aculeata Mill.) addition \\ Desarrollo y caracterización de hamburguesa de garbanzos veganos (Cicer arietinum $\mathrm{L}$.) con \\ adicion de ora-pro-nobis (Pereskia aculeata Mill.)
}

\section{Resumo}

O objetivo do presente trabalho foi desenvolver e caracterizar diferentes formulações de hambúrguer vegano de grão de bico com adição de ora-pro-nóbis e verificar a aceitação dos produtos. Neste trabalho, foram desenvolvidas quatro formulações com diferentes proporções de grão de bico (Cicer arietinum L.) e ora-pro-nóbis (Pereskia aculeata Mill): Formulação 1 (100\% grão de bico), Formulação 2 (95\% grão de bico e 5\% ora-pro-nóbis), Formulação 3 (90\% grão de bico e 10\% ora-pro-nóbis) e Formulação 4 (85\% grão de bico e 15\% ora-pro-nóbis). Foram realizadas as análises de composição proximal: umidade, proteínas, fibras, lipídeos, cinzas e carboidratos, valor energético, além das análises de atividade de água, acidez total titulável, $\mathrm{pH}$ e parâmetros de cor dos hambúrgueres crus e da folha de orapro-nóbis. Bem como análise sensorial, por meio do teste de aceitação e intenção de compra dos hambúrgueres. A adição de folhas de ora-pro-nóbis nas formulações acarretou no aumento do teor de umidade e Aw, não alterando a acidez e pH dos hamburgueres. Em relação a análise de cor, maiores porcentagens de ora-pro-nóbis nas formulações, reduziram a luminosidade dos hamburgueres (diminuição do $\mathrm{L}^{*}$ ), e as tonalidades vermelho (diminuição de $\mathrm{a}^{*}$ ) e amarelo (diminuição de $b^{*}$ ). Em relação a analise sensorial verifica-se que as formulações com maiores notas para os atributos foram F1 e F3. Considerando os resultados, o hambúrguer com adição de 10\% de folhas de ora-pro-nóbis foi o mais aceito, sugerindo maior potencial para a comercialização.

Palavras-chave: Caracterização química; Parâmetros de cor; Teste de aceitação.

\begin{abstract}
The objective of the present work was to develop and characterize different formulations of chickpeas vegan hamburger with ora-pro-nóbis addition and verify the products acceptability. In this work, four formulations were developed with different proportions of chickpea (Cicer arietinum L.) and ora-pro-nóbis (Pereskia aculeata Mill): Formulation 1 (100\% chickpeas), Formulation 2 (95\% chickpeas and 5\% ora-pro-nóbis), Formulation 3 (90\% chickpeas and 10\% ora-pro-nóbis) and Formulation 4 (85\% chickpeas and 15\% ora-pro-nóbis). Analyzes of proximal composition: moisture, proteins, fibers, lipids, ashes and carbohydrates, energetic value, as well as analyzes of water activity, total titratable acidity, $\mathrm{pH}$ and color parameters of raw hamburgers and ora-pro-nóbis leaf carried out. As well as sensory analysis, by the hamburguer acceptance test and purchase intention. The addition of ora-pro-nóbis leaves in the formulations resulted in moisture content and Aw increase, without altering the total titratable acidity and $\mathrm{pH}$. In relation of color parameters, higher percentages of ora-pro- nóbis in the formulations reduced the hamburguers luminosity (decrease of $\mathrm{L}^{*}$ ), the red color (decrease of $\mathrm{a}^{*}$ ) and yellow color (decrease of $\mathrm{b}^{*}$ ). About sensorial analyses, it was verified that the samples with the heist score for attributes were F1 and F3. Considering the
\end{abstract}


results, the hamburger with addition of $10 \%$ of ora-pro-nóbis leaves was the most accepted suggesting higher commercialization potential.

Keywords: Chemical characterization; Color parameters; Acceptance test.

\section{Resumen}

El objetivo del presente trabajo fue desarrollar y caracterizar diferentes formulaciones de hamburguesa de garbanzo vegana con el agregado de ora-pro-nóbis y verificar la aceptación de los productos. En este trabajo se desarrollaron cuatro formulaciones con diferentes proporciones de garbanzos (Cicer arietinum L) y ora-pro-nobis (Pereskia aculeata Mill): Formulación 1 (100\% garbanzos), Formulación 2 (95\% garbanzos y 5\% ora-pro-nobis), Formulación 3 (90\% garbanzos y 10\% ora-pro-nobis), Formulación 4 (85\% garbanzos y 15\% ora-pro-nobis) Se realizaron análisis de composición proximal: humedad, proteínas, fibra, lípidos, cenizas y carbohidratos, valor energético, además del análisis de actividad de agua, acidez total titulable, $\mathrm{pH}$ y parámetros de color de hamburguesas crudas y hoja de orapro-nóbis prueba de aceptación e intención de compra de las hamburguesas. La adición de hojas de ora-pro-nóbis en las formulaciones resultó en un aumento en el contenido de humedad y Aw, no cambiando la acidez y pH de las hamburguesas. En cuanto al análisis de color, mayores porcentajes de ora-pro-nóbis en las formulaciones, redujeron el brillo de las hamburguesas (reducción de la $\mathrm{L}^{*}$ ), y el tonali rojo (disminución de $\mathrm{a}^{*}$ ) y amarillo (disminución de $\mathrm{b}^{*}$ ). En relación al análisis sensorial, se verifica que las formulaciones con mayores puntuaciones para los atributos fueron F1 y F3. Considerando los resultados, la hamburguesa con la adición de un 10\% de hojas de ora-pro-nóbis fue la más aceptada, sugiriendo un mayor potencial de comercialización.

Palabras clave: Caracterización química; Parámetros de color; Examen de ingreso.

\section{Introdução}

O vegetarianismo é uma dieta baseada no princípio do não consumo de produtos cárneos e seus derivados, contudo, a definição não é precisa, pois pessoas que consomem em sua dieta ovos e produtos derivados do leite, também se declaram vegetarianas. O veganismo, por outro lado, é uma ramificação da dieta vegetariana, e é baseado no sentimento ético, onde o vegano não consome nenhum tipo de produto ou serviço de origem animal, sendo estes: alimentos, roupas, acessórios, calçados, produtos testados em animais, utilização de animais em pesquisas científicas e utilização de animais como entretenimento (Abonizio, 2013).

Segundo IBOPE Inteligência (2018), no Brasil, 14\% da população se declara vegetariana, o equivalente a quase 30 milhões de brasileiros adeptos a esta opção alimentar. Segundo a Sociedade Vegetariana Brasileira (2017), o mercado vegetariano voltado para este tipo de dieta vem crescendo e reflete tendências mundiais e, com isso, o número de produtos e serviços destinados a este segmento de mercado também aumentará.

Entretanto, devido à alta procura por alimentos mais saudáveis, a indústria desenvolveu produtos, voltados a vegetarianos e veganos, que apresentam em sua formulação ingredientes baratos e menos saudáveis, que levam os consumidores a crerem que por serem de origem vegetal são mais saudáveis que produtos de origem animal (Argüelles, 2018).

Produtos voltados para esse nicho de mercado ainda são poucos, quando comparados aos não vegetarianos, no entanto, segundo Rocha et al. (2008), devido a vasta biodiversidade de plantas existentes no Brasil, é possível encontrar hortaliças não convencionais, como por exemplo a ora-pro-nóbis, ricas em nutrientes e minerais, que apresentam um alto valor nutricional, de fácil cultivo e baixo custo; que podem ser utilizadas para agregar valor aos produtos vegetarianos e veganos. Contudo, segundo Pinto (1999), o consumo dessas hortaliças é reduzido devido à falta de conhecimento quanto ao valor nutricional e modo de preparo.

A Pereskia aculeata Mill. (ora-pro-nóbis), é uma hortaliça não convencional, que apesar de ter sido pouco estudada cientificamente, apresenta em média 20\% de teor proteico, além de elevados valores de aminoácidos essenciais (Mazia, 2012; Rocha, et al., 2008). Já o grão de bico, segundo Zia-Ul-Haq et al. (2007) é uma fonte proteica acessível, de alta qualidade e uma boa fonte de glúcidos, minerais e oligoelementos.

Com base neste contexto o objetivo do presente trabalho foi desenvolver e caracterizar diferentes formulações de hambúrgueres vegano de grão de bico com adição de ora-pro-nóbis e verificar a aceitação dos produtos. 
Deste modo, devido ao aumento no número de pessoas que buscam uma alimentação mais saudável e/ou alternativa e o número reduzido de produtos disponíveis no mercado, o presente estudo pretende oferecer uma alternativa proteica de qualidade e que seja sensorialmente aceita pelo público-alvo. Além dos vegetarianos e veganos, pessoas com doença celíaca, alergênicos ou intolerantes ao glúten poderão consumir o produto, pois em sua formulação possui apenas grão de bico, ora-pronóbis e condimentos.

\section{Metodologia}

O trabalho foi desenvolvido nos laboratórios da Faculdade de Engenharia, na Universidade Federal da Grande Dourados - UFGD. As matérias-primas para produção dos hambúrgueres foram obtidas em mercado local, na região de Dourados-MS. As folhas de ora-pro-nóbis foram obtidas no horto da Universidade Federal da Grande Dourados. Para o processamento foi utilizado grão de bico, ora-pro-nóbis, água, páprica doce, sal, óleo de milho, alho em pó, cebola em pó, carboximetilcelulose, pimenta do reino em pó e açafrão em pó. Esta pesquisa é de natureza experimental e quantitativa e foi realizada utilizando procedimentos metodológicos proposto por Pereira et al., (2018).

\subsection{Obtenção da farinha de grão de bico e folhas de ora-pro-nóbis (Pereskia aculeata Mill)}

Para a elaboração da farinha, o grão de bico foi adquirido no mercado local e levado aos laboratórios da Faculdade de Engenharia, onde foi moído em Moinho de Facas tipo Willey (modelo SL-31).

As folhas de ora-pro-nóbis (Pereskia aculeata Mill) foram coletadas no horto da Universidade Federal da Grande Dourados e levadas aos laboratórios da Faculdade de Engenharia, onde removeu-se as folhas dos galhos para posterior lavagem em água corrente e sanitização em solução de 1 litro de água para $15 \mathrm{~mL}$ de hipoclorito de sódio, por 10 minutos. Após esse período, foram enxaguadas em água corrente.

\subsection{Elaboração dos hambúrgueres de grão de bico com adição de ora-pro-nóbis (Pereskia aculeata Mill)}

Foram desenvolvidas quatro formulações com diferentes proporções de grão de bico e ora-pro-nóbis (Pereskia aculeata Mill), sendo que: F1 (100\% grão de bico), F2 (95\% grão de bico e 5\% ora-pro-nóbis), F3 (90\% grão de bico e 10\% ora-pro-nóbis), F4 (85\% grão de bico e $15 \%$ ora-pro-nóbis).

As porcentagens dos demais ingredientes utilizados foram calculados a partir da base (grão de bico + ora-pro-nóbis) e mantidos fixos para todas as formulações. Conforme Tabela 1. A proporção adequada de cada ingrediente foi determinada previamente, através de testes, até a obtenção de produtos com propriedades sensoriais agradáveis. 
Tabela 1. Formulações dos hambúrgueres de grão de bico com ora-pro-nóbis.

\begin{tabular}{lllll}
\hline Ingredientes & $\mathbf{F 1}(\boldsymbol{\%})$ & $\mathbf{F 2}(\boldsymbol{\%})$ & $\mathbf{F 3}(\boldsymbol{\%})$ & $\mathbf{F 4}(\boldsymbol{\%})$ \\
\hline Grão de Bico & 100,0 & 95,0 & 90,0 & 85,0 \\
Ora-pro-nóbis & 0 & 5,0 & 10,0 & 15,0 \\
Água & 75,0 & 75,0 & 75,0 & 75,0 \\
Páprica doce & 2,6 & 2,6 & 2,6 & 2,6 \\
Sal & 3,0 & 3,0 & 3,0 & 3,0 \\
Óleo de milho & 2,0 & 2,0 & 2,0 & 2,0 \\
Alho em pó & 1,5 & 1,5 & 1,5 & 1,5 \\
Cebola em pó & 1,2 & 1,2 & 1,2 & 1,2 \\
Carboximetilcelulose & 1,0 & 1,0 & 1,0 & 1,0 \\
Pimenta do reino & 0,5 & 0,5 & 0,5 & 0,5 \\
Açafrão & 0,1 & 0,1 & 0,1 & 0,1 \\
\hline
\end{tabular}

F1= Controle (Sem adição de ora-pro-nóbis), F2=Adição de 5\% de ora-pro-nóbis, F3= Adição de 10\% de ora-pronóbis, F4= Adição de 15\% de ora-pro-nóbis. Fonte: Autores.

Após a pesagem de todos os ingredientes, estes foram homogeneizados manualmente e mantidos em repouso por 30 minutos sob refrigeração $\left(6^{\circ} \mathrm{C}\right)$, para dar melhor consistência. Os produtos foram moldados na formadora de hambúrgueres, utilizando papel manteiga e acondicionados em sacos de polietileno e armazenados sob congelamento $\left(-14{ }^{\circ} \mathrm{C}\right)$.

Para os testes sensoriais as amostras dos hambúrgueres de grão de bico com ora- pro-nóbis (Pereskia aculeata Mill) foram assadas a $200{ }^{\circ} \mathrm{C}$, de 30-40 minutos. Para determinação da composição proximal, análises químicas e físicas foram utilizadas as amostras cruas.

\subsection{Análises Químicas}

As determinações de umidade, lipídios, cinzas e fibras dos hambúrgueres foram realizadas de acordo com os métodos oficiais da AOAC (2012). A umidade foi determinada em estufa a $105^{\circ} \mathrm{C}$, após 6 horas as amostras foram pesadas e a umidade calculada pela diferença de massa. As cinzas foram determinadas por incineração em mufla a $550^{\circ} \mathrm{C}$. $\mathrm{O}$ teor de lipídeos foi obtido pelo método Bligh e Dyer. O teor de fibra bruta foi determinado por meio da dissolução da amostra, sucessivamente em solução ácida e básica. As proteínas foram determinadas pelo método de Kjeldahl descrito pela AOAC (2012), utilizando 6,25 como fator de correção. Os carboidratos totais foram quantificados pelo cálculo teórico (por diferença), conforme a Equação 1:

$\%$ Carboidratos $=100-(\%$ umidade $+\%$ proteína $+\%$ lipídios $+\%$ cinzas $+\%$ fibra bruta $)$

O Valor energético foi quantificado utilizando os seguintes fatores de conversão, conforme a Equação 2:

Valor energético $\left(\mathrm{kcal} .100 \mathrm{~g}^{-1}\right)=\%$ carboitrado $* 4+\%$ proteína $* 4+\%$ lipídios $* 9$

As análises de $\mathrm{pH}$, atividade de água e acidez total titulável foram realizadas seguindo a metodologia descrita pela AOAC (2012), em triplicata. Para determinação do pH, as amostras foram diluídas em água. A medida foi realizada utilizandose potenciômetro, no líquido sobrenadante após decantação dos sólidos.A atividade de água foi determinada, diretamente em medidor eletrônico, modelo Aqualab lite (Decagon), à temperatura constante $\left(25,0 \pm 0,30{ }^{\circ} \mathrm{C}\right)$. A acidez foi determinada 
através de titulação com $\mathrm{NaOH}$, com normalidade igual a 0,1 .

\subsection{Análises Físicas}

Para a determinação da cor instrumental, utilizou-se o colorímetro (Minolta Chroma Meter CR 410), onde a cor é expressa pelo sistema CIELAB. Os parâmetros utilizados são: $L^{*}, a^{*}$ e b* $\left(L^{*}=\right.$ luminosidade; $a^{*}=$ intensidade de vermelho; $\mathrm{b}^{*}=$ intensidade de amarelo). Realizou a análise em 5 repetições na parte externa das amostras. Foram calculados o valor de croma $C^{*}$ e h e a diferença de cor $(\Delta E)$ entre os hambúrgueres.

\subsection{Análise Sensorial}

O teste de aceitação foi aplicado utilizando-se de escala hedônica estruturada de 9 pontos, onde 9 = gostei muitíssimo; 8 = gostei muito; $7=$ gostei moderadamente; $6=$ gostei ligeiramente; $5=$ nem gostei, nem desgostei; $4=$ desgostei ligeiramente; 3 = desgostei moderadamente; 2 = desgostei muito e 1 = desgostei muitíssimo. Cada amostra foi avaliada por um painel de cem consumidores, no Laboratório de Análise Sensorial - LANASE, da UFGD.

As amostras foram apresentadas de forma monádica aos provadores, codificadas ao acaso com números de três dígitos. Os provadores foram indagados quanto aos atributos cor, aroma, sabor e aceitação global dos hamburgueres elaborados com grão de bico e ora-pro-nóbis.

Na mesma ficha foi avaliada a intenção de compra, onde utilizou-se escala hedônica de 5 pontos, variando de 5 (certamente compraria) a 1 (certamente não compraria) (Ferreira, et al., 2000). A intenção de compra foi analisada por meio de histogramas de frequência.

\subsection{Análise Estatística}

Os resultados das análises de caracterização foram tratados estaticamente através da análise de variância (ANOVA) e as médias comparadas pelo teste de Tukey ao nível de 5\% de significância, utilizando software estatístico.

\section{Resultados e Discussão}

\subsection{Análises Químicas das folhas de ora-pro-nóbis e dos hambúrgueres}

A Tabela 2 apresenta os resultados da composição proximal e valor energético das folhas de ora-pro-nóbis e dos hambúrgueres elaborados com grão de bico e ora-pro- nóbis (Pereskia aculeata Mill). 
Tabela 2. Composição proximal dos hambúrgueres elaborados com grão de bico e ora-pro-nóbis e das folhas de ora-pro-nóbis.

\begin{tabular}{llllll}
\hline Determinações & F1 & F2 & F3 & F4 & Folha \\
\hline Umidade (\%) & $44,55^{\mathrm{c}} \pm 0,629$ & $43,30^{\mathrm{c}} \pm 0,984$ & $46,80^{\mathrm{b}} \pm 0,248$ & $49,58^{\mathrm{a}} \pm 0,446$ & - \\
Proteínas (\%) & $9,59^{\mathrm{a}, \mathrm{b}} \pm 0,079$ & $10,72^{\mathrm{a}} \pm 0,644$ & $8,92^{\mathrm{b}} \pm 0,823$ & $9,42^{\mathrm{a}, \mathrm{b}} \pm 0,440$ & $23,11 \pm 0,363$ \\
Fibras (\%) & $5,15^{\mathrm{a}} \pm 0,607$ & $3,71^{\mathrm{b}} \pm 0,084$ & $3,20^{\mathrm{b}} \pm 0,114$ & $3,12^{\mathrm{b}} \pm 0,091$ & $18,29 \pm 0,153$ \\
Lipídeos (\%) & $3,09^{\mathrm{b}} \pm 0,410$ & $3,50^{\mathrm{a}, \mathrm{b}} \pm 0,107$ & $3,82^{\mathrm{a}} \pm 0,286$ & $4,18^{\mathrm{a}} \pm 0,107$ & $9,34 \pm 0,185$ \\
Cinzas (\%) & $1,04^{\mathrm{ns}} \pm 0,356$ & $1,40^{\mathrm{ns}} \pm 0,426$ & $1,05^{\mathrm{ns}} \pm 0,146$ & $1,33^{\mathrm{ns}} \pm 0,112$ & $7,80 \pm 0,031$ \\
Carboidratos (\% & 36,59 & 37,36 & 36,21 & 32,37 & 6,05 \\
Valor energético & 212,54 & 223,82 & 214,82 & 204,75 & 49,93 \\
(kcal.100g $^{-1}$ ) & & & & &
\end{tabular}

Letras diferentes na mesma linha indicam que as amostras diferem entre si $(\mathrm{p} \leq 0,05)$ pelo Teste de Tukey. Cálculos realizados em base seca. ns=não houve diferença significativa entre as amostras (p>0,05). F1 (100\% grão de bico), F2 (95\% grão de bico, $5 \%$ ora-pro-nóbis), F3 (90\% grão de bico, $10 \%$ ora-pro- nóbis), F4 (85\% grão de bico, $15 \%$ orapro-nóbis), Folha (Folha de ora-pro-nóbis). Fonte: Autores.

Observando a Tabela 2, em relação a umidade, é possível afirmar que os hambúrgueres apresentaram alto teor de umidade, variando de 43,30 a 49,58\%, para as Formulações F2 e F4, respectivamente. A Formulação 1 e Formulação 2 apresentaram menor umidade e não apresentaram diferença significativa entre si (p>0,05), contudo ambas diferiram de F3 e F4 $(\mathrm{p} \leq 0,05)$. A adição de ora-pro-nóbis à massa pode ter acarretado no aumento da umidade nas formulações.

Hambúrgueres de caju estudados por Lima (2007) apresentaram valores de umidade de 49,47\%. Valor próximo ao estudado no presente trabalho.

Como demonstrado na Tabela 2, os teores de proteínas variaram de 8,92 a 10,72\%, para as Formulações F3 e F2, respectivamente. As Formulações F2 e F3 apresentaram diferença significativa entre si $(\mathrm{p} \leq 0,05)$ e ambas não diferiram das Formulações F1 e F4 (p>0,05).

Lima (2018) ao estudar adição de resíduo de acerola em hambúrgueres de grão de bico encontrou valores entre 4,84 a 7,20\% para proteínas. Já Lima (2008) encontrou valores entre 5,04 a 12,95\% em hambúrgueres de proteína vegetal, e 5,75\% para hambúrgueres de caju.

A folha de ora-pro-nóbis apresentou $23,11 \%$ de proteínas, conforme Tabela 2, valores próximos foram encontrados por Silveira (2016), que encontrou uma porcentagem de 23,34. Variações no teor proteico da folha podem estar relacionados à composição do solo, modo de cultivo e espécie (Mazia; Sartor, 2012).

De acordo com a Tabela 2, os valores de fibras variaram de 3,12 a 5,15\% para as Formulações F4 e F1, respectivamente. A Formulação 1 apresentou diferença significativa das demais formulações $(\mathrm{p} \leq 0,05)$.

Os hambúrgueres de grão de bico com adição de resíduo de acerola de Lima (2018) apresentaram valores entre 3,92 e 4,52\% para fibras. Já Leme (2012), obteve uma porcentagem de fibras de 12,49\% em hambúrguer de caju.

A folha de ora-pro-nóbis apresentou $18,29 \%$ de fibras, conforme a Tabela 2 . Silveira (2016) encontrou 43,47\% de fibras na folha de ora-pro-nóbis. Essa diferença pode ser devido ao método de determinação.

Na Tabela 2 verifica-se que os teores de lipídeos variaram de 3,09 a 4,18\%, para as Formulações F1 e F4, respectivamente. A Formulação F1 apresentou diferença significativa das amostras F3 e F4 (p $\leq 0,05)$. Sugerindo que a adição da hortaliça acarretou em um aumento de lipídeos no hambúrguer de grão de bico. Lima (2018) encontrou variações de 3,25 a 6,55\% de lipídeos em suas formulações de hambúrgueres de grão de bico com adição de resíduo de acerola. Leme (2012) 
obteve valores de 8,28\% de lipídeos em hambúrgueres a base de caju.

A folha da ora-pro-nóbis apresentou teor de lipídeos de 9,34\%, como observado na Tabela 2. Silveira (2016), encontrou 1,44\% de lipídeos em folhas, da mesma espécie, de ora-pro-nóbis.

Pela Tabela 2, o teor de cinzas variou de 1,04 a 1,40\% para as Formulações F1 e F2, respectivamente. As Formulações não apresentaram diferença significativa entre si $(p>0,05)$. Sugerindo que a adição de ora-pro-nóbis não afetou o teor de cinza dos hamburgueres. Lima (2018) encontrou valores de cinzas de 1,51 a 1,77\%, em hambúrgueres de grão de bico com adição de resíduo de acerola. Já Lima (2008), encontrou uma variação de 3,40 a 4,75\%, de cinzas, em hambúrgueres de proteína vegetal e 2,89 por cento, em hambúrguer a base de caju.

De acordo com a Tabela 2, a folha de ora-pro-nóbis apresentou 7,80\% de cinzas. Em folhas da mesma espécie, Silveira (2016) encontrou $20,64 \%$ de cinzas.

Como demonstrado na Tabela 2, o maior conteúdo de carboidrato foi de 37,36\% para a formulação 2. As formulações F1 e F3 apresentaram teor de carboidratos de 36,59\% e 36,21\%, respectivamente; o menor teor de glicídico foi a F4 com valor de $32,37 \%$.

Lima (2018), encontrou em hambúrgueres de grão de bico com resíduo de acerola, valores de 23,46\% a 27,96\% de carboidratos, onde o menor teor de carboidratos foi na formulação com maior adição de resíduo de acerola (50\%).

De acordo com a Tabela 2, a folha de ora-pro-nóbis apresentou 6,05\% de carboidratos. Já o grão de bico, segundo Aurelia (2009), apresenta 57,88\% de carboidratos (base úmida). Levando em consideração essas informações, supõe-se que, a substituição da farinha de grão de bico por ora-pro-nóbis nas formulações, acarreta na redução do teor de carboidratos por substituir um ingrediente com alto teor glicídico por um com menor teor.

Os hambúrgueres apresentaram conteúdo calórico com valores, em ordem decrescente de 223,82, 214,82, 212,54 e 204,75 kcal.100g ${ }^{-1}$ para F2, F3, F1 e F4, respectivamente. Supõe-se que, a adição da hortaliça alterou apenas ligeiramente o conteúdo energético do produto. Lima (2018) encontrou valores inferiores, que variaram de 142,45 a $199,59 \mathrm{kcal} .100 \mathrm{~g}^{-1}$ para hambúrgueres de grão de bico com resíduo de acerola.

A Tabela 3 apresenta os resultados das análises químicas dos hambúrgueres elaborados com grão de bico e ora-pronóbis (Pereskia aculeata Mill).

Tabela 3. Resultados das análises químicas dos hambúrgueres elaborados com grão de bico e ora-pro-nóbis.

\begin{tabular}{clllll}
\hline Determinações & $\mathbf{F 1}$ & $\mathbf{F 2}$ & $\mathbf{F 3}$ & $\mathbf{F 4}$ & Folha \\
\hline $\begin{array}{c}\text { Atividade de } \\
\text { água (Aw) }\end{array}$ & $0,938^{\mathrm{c}} \pm 0,006$ & $0,951^{\mathrm{b}} \pm 0,001$ & $0,960^{\mathrm{a}} \pm 0,001$ & $0,965^{\mathrm{a}} \pm 0,001$ & $0,976 \pm 0,001$ \\
$\begin{array}{c}\text { Acidez Tituláve } \\
\left(\mathbf{g} . \mathbf{1 0 0 g ^ { - 1 }}\right)\end{array}$ & $0,459^{\mathrm{ns}} \pm 0,015$ & $0,459^{\mathrm{ns}} \pm 0,015$ & $0,469^{\mathrm{ns}} \pm 0,000$ & $0,448^{\mathrm{ns}} \pm 0,00$ & $0,043 \pm 0,00$ \\
$\mathbf{p H}$ & $6,183^{\mathrm{ns}} \pm 0,042$ & $6,167^{\mathrm{ns}} \pm 0,040$ & $6,193^{\mathrm{ns}} \pm 0,035$ & $6,243^{\mathrm{nn}} \pm 0,015$ & $5,033 \pm 0,067$ \\
\hline
\end{tabular}

Letras diferentes na mesma linha indicam que as amostras diferem entre si $(p \leq 0,05)$ pelo Teste de Tukey. ns=não houve diferença significativa entre as amostras (p>0,05). F1 (100\% grão de bico), F2(95\% grão de bico, 5\% ora-pronóbis), F3(90\% grão de bico, $10 \%$ ora-pro- nóbis), F4(85\% grão de bico, 15\% ora-pro-nóbis), Folha (Folha de orapro-nóbis). Fonte: Autores.

Os valores de atividade de água (Aw), apresentados na Tabela 3, variaram de 0,938 a 0,965 para as formulações F1 e F4, respectivamente. A Formulação F4 não diferiu da F3 (p>0,05) e ambas diferiram das formulações F2 e F1 (p $\leq 0,05)$; F2 diferiu de F1 $(\mathrm{p} \leq 0,05)$. Assim como a umidade, os valores encontrados para atividade de água, aumentam conforme a adição de ora-pro-nóbis nas formulações. 
Os hambúrgueres apresentam risco de contaminação, devido à alta umidade e atividade de água, com isso, os mesmos devem ser conservados sob a forma de congelamento. Lima (2018), encontrou valores de 0,949 e 0,979 para hambúrguer de grão de bico sem resíduo de acerola e com adição de 50\% de resíduo de acerola, respectivamente. Já Lima (2008) encontrou valores de 0,958 e 0,983 para hambúrgueres de proteína vegetal.

A acidez titulável variou de 0,448 a $0,469 \mathrm{~g} .100 \mathrm{~g}^{-1}$ para as Formulações F4 e F3, respectivamente, conforme mostra a Tabela 3. As amostras não apresentaram diferença significativa entre si ( $>0,05)$. Sugerindo que a adição da hortaliça não influenciou este parâmetro. Leme (2012) encontrou valor de acidez titulável de $0,30 \mathrm{~g} \cdot 100 \mathrm{~g}^{-1} \mathrm{em}$ hambúrguer de caju e Lima (2013) de $0,29 \mathrm{~g} \cdot 100 \mathrm{~g}^{-1} \mathrm{em}$ hambúrguer de fibra de caju e feijão-caupi.

$\mathrm{O}$ pH variou de 6,167 a 6,243 para as formulações F2 e F4, respectivamente, conforme apresentados na Tabela 3. As amostras não apresentaram diferença significativa entre si $(\mathrm{p}>0,05)$. $\mathrm{O}$ elevado $\mathrm{pH}$ confirma a necessidade de armazenamento do produto sob congelamento. Lima (2018), encontrou valores entre 6,12 e 6,20 em hambúrgueres de grão de bico e Lima (2008), entre 6,60 e 6,78 em hambúrgueres de proteína vegetal.

De acordo com a Tabela 3, a folha de ora-pro-nóbis apresentou Aw de 0,976, sendo esta maior que as das formulações. Em relação a acidez e pH, apresentou 0,043 g.100g-1 e 5,033, respectivamente, sendo estes, inferiores as formulações de hambúrgueres do presente trabalho.

\subsection{Análises Físicas}

A Tabela 4 apresenta os valores dos parâmetros da análise de cor instrumental ( $\mathrm{L}^{*}, \mathrm{a}^{*}$ e b*, $\mathrm{C}^{*}, \mathrm{~h}$ e $\left.\Delta \mathrm{E}\right) \operatorname{dos}$ hambúrgueres elaborados com grão de bico e ora-pro- nóbis (Pereskia aculeata Mill) e da folha de ora-pro-nóbis.

Tabela 4. Valores dos parâmetros da cor instrumental ( $L^{*}, a^{*}$ e b*) dos hambúrgueres elaborados com grão de bico e ora-pronóbis e da folha de ora- pro-nóbis.

\begin{tabular}{llllll}
\hline Determinações & F1 & F2 & F3 & F4 & Folha \\
\hline $\mathbf{L}^{*}$ & $59,60^{\mathrm{a}} \pm 0,79$ & $56,84^{\mathrm{b}} \pm 0,36$ & $56,98^{\mathrm{b}} \pm 0,30$ & $57,10^{\mathrm{b}} \pm 1,10$ & $44,22 \pm 0,34$ \\
$\mathbf{a}^{*}$ & $12,73^{\mathrm{a}} \pm 0,36$ & $11,38^{\mathrm{b}} \pm 0,73$ & $8,40^{\mathrm{c}} \pm 0,45$ & $6,54^{\mathrm{d}} \pm 0,66$ & $-9,11 \pm 0,20$ \\
$\mathbf{b}^{*}$ & $34,49^{\mathrm{a}} \pm 1,01$ & $31,83^{\mathrm{b}} \pm 0,95$ & $31,24^{\mathrm{b}} \pm 1,02$ & $28,22^{\mathrm{c}} \pm 1,33$ & $12,46 \pm 0,41$ \\
$\mathbf{C}^{*}$ & $36,77^{\mathrm{a}} \pm 0,98$ & $33,81^{\mathrm{b}} \pm 0,99$ & $32,35^{\mathrm{b}} \pm 1,08$ & $28,97^{\mathrm{c}} \pm 1,34$ & $15,43 \pm 0,40$ \\
$\mathbf{h}$ & $0,39^{\mathrm{a}} \pm 0,02$ & $0,37^{\mathrm{a}} \pm 0,03$ & $0,28^{\mathrm{b}} \pm 0,01$ & $0,24^{\mathrm{b}} \pm 0,02$ & $-0,93 \pm 0,05$ \\
$\Delta \mathbf{E}$ & - & 4,06 & 6,02 & 9,16 & - \\
\hline
\end{tabular}

Letras diferentes na mesma linha indicam que as amostras diferem entre si $(\mathrm{p} \leq 0,05)$ pelo Teste de Tukey. Legenda $=$ $L^{*}$ luminosidade; $a^{*}$ coordenada verde(-)/vermelho(+); b* coordenada azul(-)/amarelo(+); $C^{*}$ croma; $h$ ângulo de tonalidade; $\Delta \mathrm{E}$ diferença total de cor; F1 (100\% grão de bico), F2(95\% grão de bico, $5 \%$ ora-pro-nóbis), F3(90\% grão de bico, $10 \%$ ora-pro-nóbis) F4(85\% grão de bico, 15\% ora-pro- nóbis), Folha (Folha de ora-pro-nóbis). Fonte: Autores.

Observa-se pela Tabela 4, que houve diferença significativa em relação ao $\mathrm{L}^{*}$ entre $\mathrm{F} 1 \mathrm{e}$ as demais formulações $(p \leq 0,05)$, sendo que F1 apresentou maior luminosidade. Com relação ao parâmetreo $a^{*}$, todas as formulações apresentaram diferença significativa entre $\mathrm{si}(\mathrm{p} \leq 0,05)$.

Para o atributo $b^{*}, F 2$ e F3 não apresentaram diferença significativa entre si (p>0,05), ambos diferiram dos demais $(\mathrm{p} \leq 0,05)$. A Formulação 1 (F1) apresentou maior valor de $\mathrm{L}^{*}, \mathrm{a}^{*} \mathrm{e} \mathrm{b}^{*}$ em relação as demais formulações, caracterizando um tom mais claro, avermelhado e amarelo, respectivamente. 
$\mathrm{O}$ valor de $\mathrm{C}^{*}$, para as Formulações $\mathrm{F} 2$ e F3, não apresentaram diferença significativa ( $\left.>>0,05\right)$ e ambas diferiram de

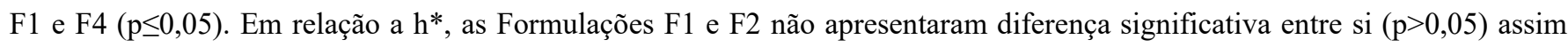
como F3 e F4 não diferiram entre si (p>0,05).

Os resultados de $\Delta \mathrm{E}$ mostram que o aumento de porcentagem de ora-pro-nóbis nas formulações de hambúrgueres aumentou a diferença de colaração em relação ao hambúrguer sem ora-pro-nóbis (F1), sendo a F4 a que apresentou maior diferença.

A folha de ora-pro-nóbis apresentou valor de $\mathrm{L}^{*}$ com ligeira tendência para o preto, $\mathrm{o} \mathrm{a}^{*}$ voltado para o tom verde e b* para o amarelo. A Figura 1 apresenta a posição das formulações no diagrama de cromaticidade.

Figura 1. Posição das formulações no diagrama de cromaticidade.

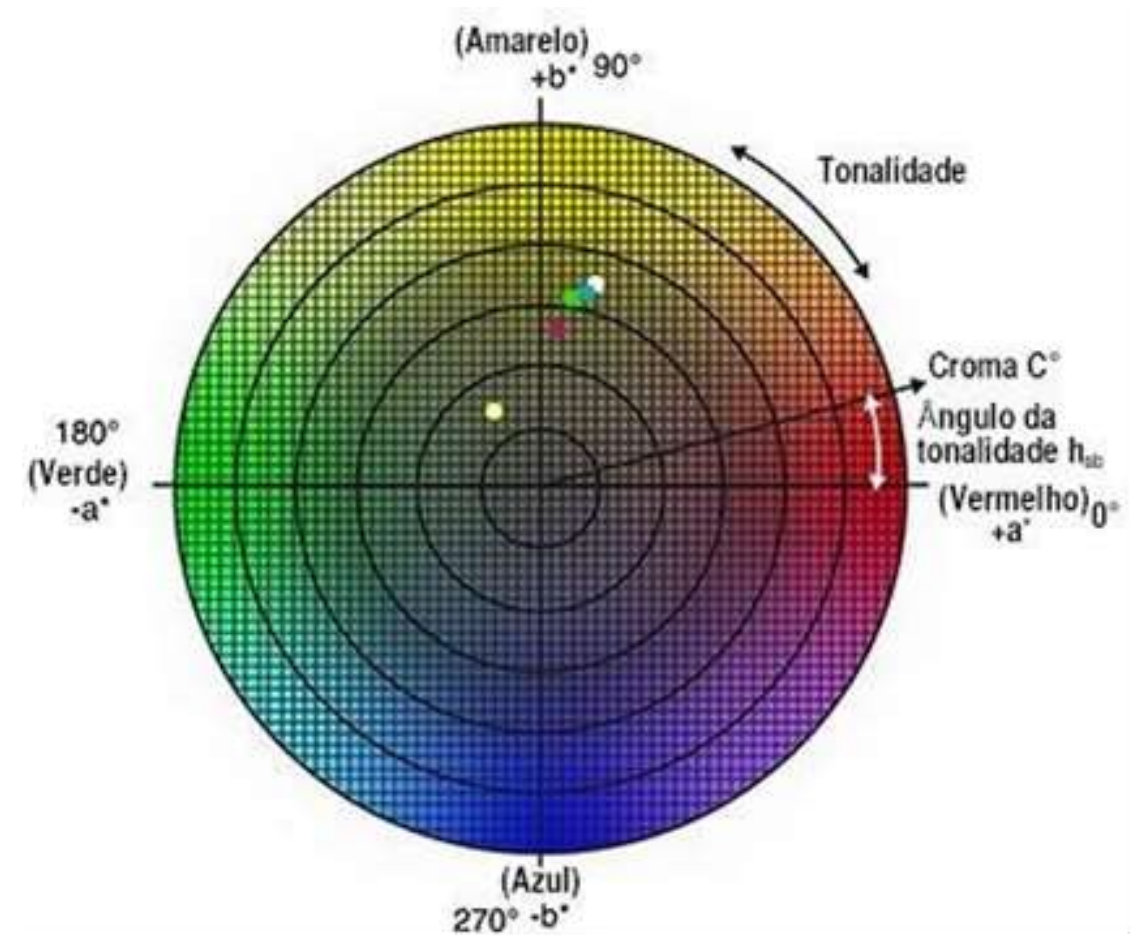

Círculo: Branco: F1(100\% grão de bico); Azul: F2 (95\% grão de bico, 5\% ora-pro-nóbis); Verde: F3 (90\% grão de bico, 10\% ora-pro-nóbis); Rosa: F4 (85\% grão de bico, 15\% ora-pro-nóbis); Amarelo: Folha. Fonte: Espaços de cores CIE XYZ, CIE L*a*b*, com alterações do autor. https://sensing.konicaminolta.us/br/blog/compreendendo-o-espaco-de-cor-cie-lch/

A ora-pro-nóbis tem influência direta na cor dos hambúrgueres, por apresentar valores de $\mathrm{L}^{*}$ com ligeira tendência para o preto, $\mathrm{a}^{*}$ mais voltado para o verde e $\mathrm{b}^{*}$ para o azul. Já que o hambúrguer controle $(\mathrm{F} 1)$ apresenta $\mathrm{L}^{*}$ voltado para o branco, a* para o vermelho e $b^{*}$ para o amarelo.

Maiores porcentagens da folha nas formulações reduz a luminosidade dos hambúrgueres (diminuição do $\mathrm{L}^{*}$ ), torna-os menos amarelos (diminuição de $b^{*}$ ) e vermelhos (diminuição de $a^{*}$ ).

\subsection{Análise Sensorial}

A Tabela 5 apresenta os valores médios dos escores obtidos pelo teste de aceitação dos hambúrgueres elaborados com grão de bico e ora-pro-nóbis (Pereskia aculeata Mill). 
Tabela 5. Valores médios dos escores pelo teste de aceitação e índices de aceitabilidade para os atributos sensoriais cor, sabor, odor, textura e aceitação global dos hambúrgueres elaborados com grão de bico e ora-pro-nóbis.

\begin{tabular}{lllll}
\hline Atributos & $\mathbf{F 1}$ & $\mathbf{F 2}$ & $\mathbf{F 3}$ & $\mathbf{F 4}$ \\
\hline Cor & $6,78^{\mathrm{ns}} \pm 1,78$ & $6,83^{\mathrm{ns}} \pm 1,60$ & $6,84^{\mathrm{ns}} \pm 1,25$ & $6,66^{\mathrm{ns}} \pm 1,66$ \\
Aroma & $6,45^{\mathrm{ns}} \pm 1,52$ & $6,47^{\mathrm{ns}} \pm 1,58$ & $6,34^{\mathrm{ns}} \pm 1,54$ & $6,17^{\mathrm{ns}} \pm 1,69$ \\
Sabor & $6,47^{\mathrm{a}, \mathrm{b}} \pm 1,75$ & $6,58^{\mathrm{a}, \mathrm{b}} \pm 1,80$ & $7,05^{\mathrm{a}} \pm 1,44$ & $6,28^{\mathrm{b}} \pm 2,02$ \\
Aceitação Global & $6,48^{\mathrm{a}, \mathrm{b}} \pm 1,72$ & $6,53^{\mathrm{a}, \mathrm{b}} \pm 1,70$ & $6,94^{\mathrm{a}} \pm 1,41$ & $6,20^{\mathrm{b}} \pm 1,90$ \\
\hline
\end{tabular}

Letras diferentes na mesma linha indicam que as amostras diferem entre si $(\mathrm{p} \leq 0,05)$ pelo Teste de Tukey. ns=não houve diferença significativa entre as amostras (p>0,05); F1 (100\% grão de bico), F2(95\% grão de bico, 5\% ora-pronóbis), F3(90\% grão de bico, $10 \%$ ora-pro-nóbis) F4(85\% grão de bico, 15\% ora- pro-nóbis). Fonte: Autores.

Por meio da análise da Tabela 5 pode-se observar que para os atributos Cor e Aroma não houve diferença significativa entre as amostras $(\mathrm{p}>0,05)$, o que indica que a adição de ora-pro-nóbis não influenciou na aceitação dos produtos pelos consumidores, com relação a esses atributos.

Já para o atributo sabor, houve diferença significativa $(\mathrm{p} \leq 0,05)$ entre as formulações F3 e F4, sendo o maior valor atribuído a formulação que continha $10 \%$ de ora-pro-nóbis. Ambas formulações não apresentaram diferença significativa $(\mathrm{p}>0,05)$ da F2 e F1.

Em relação a aceitação global, houve diferença significativa $(p \leq 0,05)$ entre as Formulações $F 3$ e $F 4$ e ambas formulações não apresentaram diferença significativa ( $p>0,05)$ da F2 e F1.

Analisando a Tabela 5 quanto as médias das notas obtidas na avaliação por escala hedônica, observa-se que, com exceção do atributo sabor, todos apresentaram valores entre 6 (gostei ligeiramente) e 7 (gostei moderadamente). Leme (2012) obteve resultados com médias entre a faixa "gostei moderadamente" e "gostei muito", já Lima (2008) para o hambúrguer de caju, obteve médias variando de "nem gostei/nem desgostei" a "gostei ligeiramente", para os mesmos atributos dos hambúrgueres em discussão.

A avaliação da intenção de compra foi realizada na mesma ocasião e complementa a análise de aceitação. O histograma de frequência pode ser observado na figura 2.

Figura 2. Intenção de compra, em porcentagem, de hambúrgueres elaborados com grão de bico e ora-pro- nóbis.

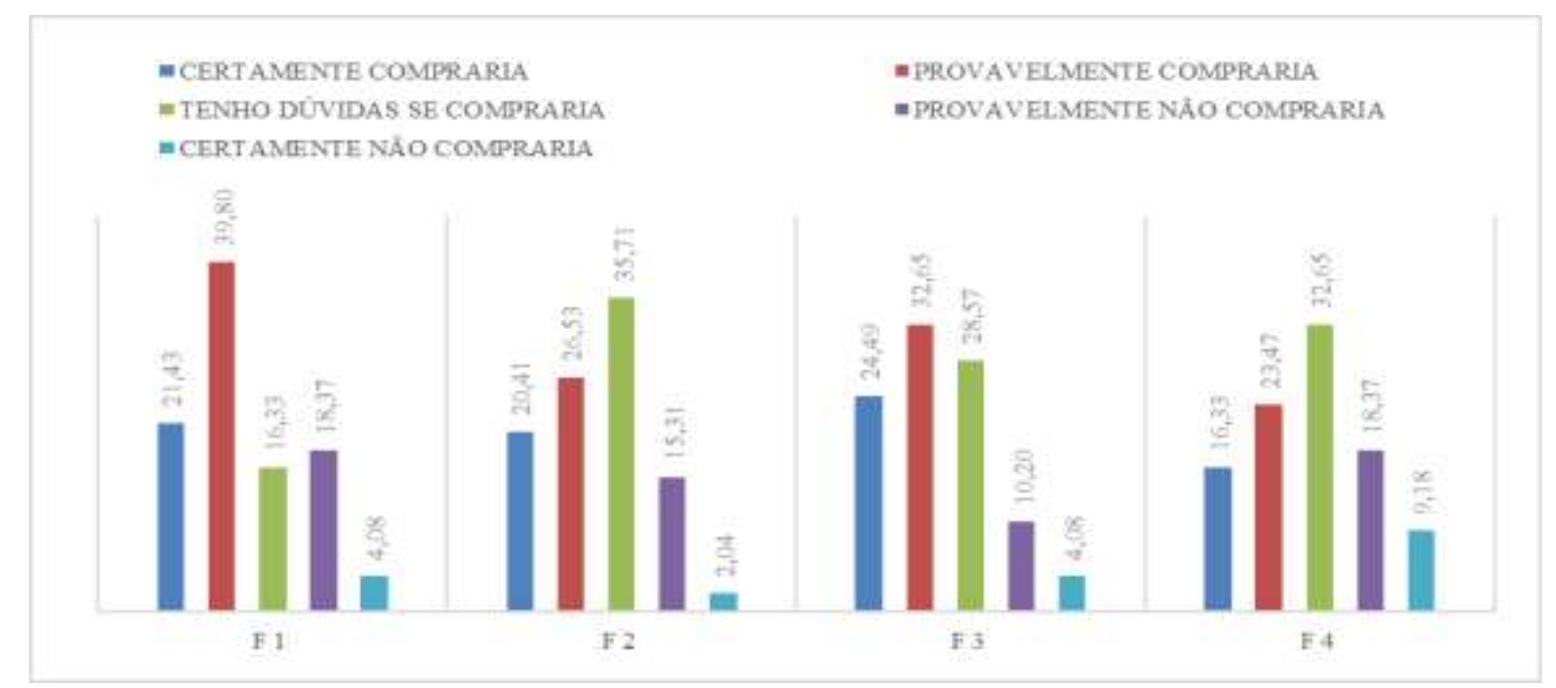

F1 (100\% grão de bico), F2 (95\% grão de bico, 5\% ora-pro-nóbis), F3 (90\% grão de bico, 10\% ora-pro-nóbis) F4 (85\% grão de bico, 15\% ora-pro-nóbis). Fonte: Autores. 
Observa-se pela Figura 2, que todos as formulações apresentaram intenção de compra positiva acima de 39,8\%, quando considerada a soma entre certamente compraria e possivelmente compraria. Os resultados obtidos para as Formulações F1, F2, F3 e F4 foram respectivamente, 61,23\%; 46,94\%; 57,14\% e 39,8\%. Com relação ao percentual de rejeição, considerando a soma das respostas como possivelmente não compraria e certamente não compraria, os resultados obtidos para as Formulações F1, F2, F3 e F4 foram respectivamente, 22,45\%; 17,35\%; 14,28\% e 27,55\%. Portanto, as formulações mais aceitas foram F1 e F3.

\section{Conclusão}

O desenvolvimento de hambúrguer vegano de grão de bico com adição de ora- pro-nóbis foi possível, sendo que a adição de folhas de ora-pro-nóbis não alterou o teor de cinzas nas formulações, todavia aumentou o teor de umidade, lipídeos e reduziu o de fibras. Em relação ao valor energético, a adição de 15\% de folhas de ora-pro-nóbis acarretou na redução do valor energético proveniente dos hambúrgueres.

Nas determinações químicas dos hambúrgueres veganos, observou-se que maiores porcentagens de ora-pro-nóbis influenciam no aumento da Aw, entretanto não alteram valores de acidez e pH.

A folha de ora-pro-nóbis apresentou quantidades consideráveis de proteínas, fibras, cinzas e Aw, além da baixa acidez e pH pouco ácido.

$\mathrm{Na}$ análise colorimétrica verificou-se que maiores porcentagens de ora-pro-nóbis nas formulações, reduziram a luminosidade $\left(\mathrm{L}^{*}\right)$, a tonalidade vermelha $\left(\mathrm{a}^{*}\right)$ e amarela $\left(\mathrm{b}^{*}\right)$. Em relação a analise sensorial verifica-se que as formulações mais aceitas foram F1 e F3. Considerando os resultados, sugere-se que a adição de 10\% de folhas de ora-pro- nóbis seria a ideal para a elaboração do hambúrguer vegano de grão de bico.

Futuros trabalhos podem utilizar as folhas de ora-pro-nóbis (Pereskia aculeata Mill), para elaboração de diferentes produtos alimentícios, tanto salgados como doces, para o público vegetariano e/ou vegano ou somente com intuito de melhorar o perfil nutricional desses produtos.

\section{Referências}

Abonizio, J. (2013). Consumo alimentar e anticonsumismo: veganos e freeganos. Ciências Sociais Unisinos, 54(2), 191-6. https://doi.org/10.4013/csu.2013.49.2.07

AOAC. (2012). Official methods of analysis of Association of the Analytical Chemists. (19a ed.), Association of Official Analytical Chemists (AOAC). Gaithersburg, MD, USA.

Argüelles, L. M. (2018). Por que é uma má notícia que a indústria se aproveite do 'boom' vegano?. https://brasil.elpais.com/brasil/2018/0 4/24/ciencia/1524564407_811902.html

Aurélia, I., Iuliana, A., Darabâ, A., Gurâu, G., Cristina, B. \& Andrei, N. (2009). Chemical and functional characterization of chickpea protein derivates. The Annals of the University of Dunarea de Jos of Galati. Fascicle VI. Food Technology. 16-27. https://citeseerx.ist.psu.edu/viewdoc/down load?doi=10.1.1.518.7428\&rep=rep1\&type=pdf

Bligh, E. G. \& Dyer, W. J. (1959). A rapid method of total lipid extration and purification. Canadian Journal of Biochemistry and Physiology. 37(8), 911-7. DOI: 10.1139 / o59-099

Ferreira, V. L. P., Almeida, T. C. A., Pettinelli, M. L. C. V, Silva, M. A. A. P., Chaves, J. B. P. \& Barbosa, E. M. M. (2000) Análise sensorial: testes discriminativos e afetivos. Campinas, SBCTA. 127p.

Ibope (2018). Ibope Inteligência Pesquisa de opinião pública sobre vegetarianismo. https://www.svb.org.br/images/Documento s/JOB_0416_VEGETARIANISMO.pdf

Leme, A. V. P. (2012) Cajubúrguer: Avaliação Físico-Química, Microbiológica e Sensorial. 56 f. TCC (Graduação) - Curso de Engenharia de Alimentos, Universidade Federal do Maranhão, Imperatriz/MA. https://monografias.ufma.br/jspui/bitstream/123456789/89/1/Monografia\%20Aline\%20Venancio.pdf

Lima, E. C. (2018). Produção de hambúrguer vegano de grão-de-bico com resíduo agroindustrial de acerola. $56 \mathrm{f}$. TCC (Graduação) - Curso de Engenharia Química, Universidade Federal do Rio Grande do Norte, Natal/RN. https://www.semanticscholar.org/paper/Produ\%C3\%A7\%C3\%A3o-dehamb\%C3\%BArguer-vegano-de-gr\%C3\%A3o-de-bico-com-Lima/10ef9a97df72e66c32a36aa3fc1ce9867facfccc 
Research, Society and Development, v. 10, n. 12, e361101220067, 2021

(CC BY 4.0) | ISSN 2525-3409 | DOI: http://dx.doi.org/10.33448/rsd-v10i12.20067

Lima, J. R., Modesto, A. L. G., Garruti, D. S., Firmino, D. S., Araújo, I. M. S. \& Moraes, I. V. M. (2013). Elaboração de Hambúrguer Vegetal de Fibra de Caju e Feijão-Caupi. Comunicado Técnico. Embrapa Agroindústria Tropical. 203, 1-6. https://www.embrapa.br/busca-de-publicacoes//publicacao/976958/elaboracao-de-hamburguer-vegetal-de-fibra-de-caju-e-feijao-caupi

Lima, J. R. (2008). Caracterização físico-química e sensorial de hambúrguer vegetal elaborado à base de caju. Ciência e Agrotecnologia. 32(1), 191-5. http://dx.doi.org/10.1590/s1413-70542008000100028

Lima, J. R. (2007). Hambúrguer de caju: elaboração e características. Comunicado Técnico. Embrapa Agroindústria Tropical. 131, 1-4. http://ainfo.cnptia.embrapa.br/digital/bitstream/CNPAT/10572/1/cot_131.pdf

Lima, J. R., Garruti, D. S., Pinto, G. A. S., Magalhães, H. C. R. \& Machado, T. F. (2017). Vegetal burgers of cashew fiber and texturized soy protein. Revista Brasileira de Fruticultura, 39(3), 1-7. https://doi.org/10.1590/0100-29452017376

Mazia, R. S., Sartor, C. F. P. (2012). Influência do tipo de solo usado para o cultivo de Pereskia aculeata sobre propriedade proteica. Revista Saúde e Pesquisa, 5(1), 59-65. https://periodicos.unicesumar.edu.br/index.php/saudpesq/article/view/2055/1555

Pereira A. S., Shitsuka, D. M., Perreira, F. J. \& Sitsuka, R. (2018). Metodologia da pesquisa científica. UFSM. https://repositorio.ufsm.br/bitstream/handle/1/1 5824/Lic_Computacao_Metodologia-Pesquisa-Cientifica.pdf?sequence=1

Pinto, N. A. V. D. et al. (1999). Caracterização mineral das folhas de taioba (Xanthosoma sagittifolium Schott). Ciência e Agrotecnologia, Lavras. 23(1), 5761 .

Rocha, D. R. C., Pereira Júnior, G. A., Vieira, G., Pantoja, L., Santos, A. S. \& Pinto, N. A. V. D. (2008). Macarrão adicionado de Ora-pro-nobis (Pereskia aculeata Miller) desidratado. Alimentos e Nutrição, Araraquara. 19(4), 459-65. http://serv-bib.fcfar.unesp.br/seer/index.php/alimentos/articl e/viewFile/656/552

Sociedade Vegetariana Brasileira. (2017). Mercado Vegetariano. https://svb.org.br/vegetarianismo1/mercado-vegetariano

Silveira, M. G. (2016). Ensaio nutricional de Pereskia spp.: Hortaliça não convencional. 174 f. Tese - Curso de Ciência dos Alimentos, Universidade Federal de Lavras. http://repositorio.ufla.br/jspui/bitstream/1/10815/2/TESE_Ensaio\%20nutricional\%20de\%20Pereskia\%20spp.\%3a\%20h ortali\%c3\%a7a\%20n\% c3\%a3o\% 20convencional.pdf

Tofanelli, M. B. D. \& Resende, S. G.(2011). Sistema de condução na produção de folhas de ora-pro-nóbis. Pesquisa Agropecuária Tropical, Goiânia. 41(3), 466-69. https://www.revistas.ufg.br/pat/article/view/12497/9733

Zia-ul-haq, M., Iqbal, S., Ahmad, S., Imran, M., Niaz, A. \& Bhanger, M. I. (2007). Nutritional and compositional study of Desi chickpea (Cicer arientinum L.) cultivars grown in Punjab, Pakistan. Food Chemistry. 105, 1357-63. https://www.researchgate.net/publication/282848750_Nutritional_and_compositional _study_of_desi_ch ickpea_Cicer_arietinum_L_cultivars_grown_in_Punjab_Pakistan 